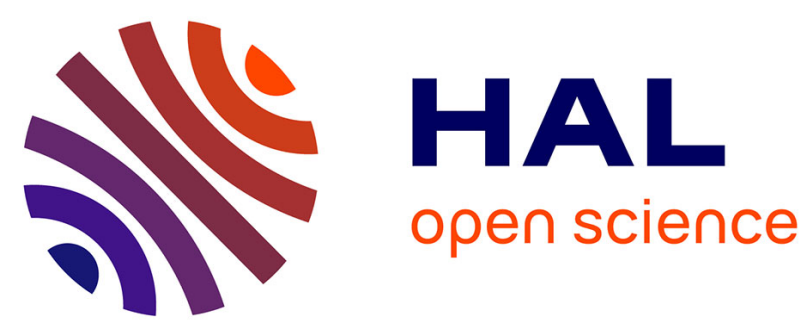

\title{
Association between Primary Open-Angle Glaucoma and WDR36 sequence variance in Italian families affected by POAG
}

Paolo Frezzotti, Chiara Pescucci, Filomena Tiziana Papa, Michele Iester, Vincenzo Mittica, Ilaria Motolese, Sabrina Peruzzi, Rosangela Artuso, Ilaria Longo, Maria Antonietta Mencarelli, et al.

\section{To cite this version:}

Paolo Frezzotti, Chiara Pescucci, Filomena Tiziana Papa, Michele Iester, Vincenzo Mittica, et al.. Association between Primary Open-Angle Glaucoma and WDR36 sequence variance in Italian families affected by POAG. British Journal of Ophthalmology, 2010, 95 (5), pp.624. 10.1136/bjo.2009.167494 . hal-00588343

\section{HAL Id: hal-00588343 https://hal.science/hal-00588343}

Submitted on 23 Apr 2011

HAL is a multi-disciplinary open access archive for the deposit and dissemination of scientific research documents, whether they are published or not. The documents may come from teaching and research institutions in France or abroad, or from public or private research centers.
L'archive ouverte pluridisciplinaire HAL, est destinée au dépôt et à la diffusion de documents scientifiques de niveau recherche, publiés ou non, émanant des établissements d'enseignement et de recherche français ou étrangers, des laboratoires publics ou privés. 


\section{Association between Primary Open-Angle Glaucoma and WDR36 sequence} variance in Italian families affected by POAG 3

Frezzotti Paolo 1, Pescucci Chiara 2, Papa Filomena Tiziana 2, Michele Iester 3 , Mittica Vincenzo

1, Motolese Ilaria 1, Peruzzi Sabrina 1, Artuso Rosangela 2, Longo Ilaria 2, Mencarelli Maria

Antonietta 2, Mittica Pietro 1, Motolese Eduardo 1, Renieri Alessandra 2

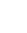

1 Ophthalmology Department, University of Siena

2 Medical Genetics, Molecular Biology Department, University of Siena

3 Clinica Oculistica, DINOG, University of Genova

Frezzotti Paolo, Pescucci Chiara, Papa Filomena Tiziana, Michele Iester, Mittica Vincenzo, Motolese Ilaria, Peruzzi Sabrina, Artuso Rosangela, Longo Ilaria, Mencarelli Maria Antonietta, Mittica Pietro Motolese Eduardo and Renieri Alessandra have not any type of financial interest related to the manuscript.

Key Words: WDR36 gene, MYOC, primary open angle glaucoma, OPTN, normal tension glaucoma

Corresponding author and reprint requests:

Paolo Frezzotti MD, PhD

Department of Ophthalmology

University of Siena

Policlinico Le Scotte

V.Le Bracci 2 - 53100, Siena

Tel 00390577233360

Fax 00390577271324

e-mail: frezzottip@unisi.it 
1 Abstract

2 Background/aims: To assess the involvement of WDR36 sequence variance in primary open-angle 3 glaucoma (POAG) in Italian patients.

4 Methods: A cohort o f 34 Italian families affected by POAG has been analyzed by Denaturing 5 High-Performance Liquid Chromatography for mutation in the WDR36 gene. Among the 34

6 families enrolled, 25 were affected by high tension glaucoma (HTG),4 by juvenile open-angle

7 glaucoma (JOAG) and 1 by normal tension glaucoma (NTG). In addition, 4 families presented 8 within the same pedigree both JOAG and HTG-POAG patients.

9 Results: Four already known intronic polymorphisms (IVS5+30C>T; IVS12+90 G>T; IVS13+89G $>A$; IVS16-30A $>$ G) and a novel one (IVS21-75G >A), have been identified. In addition,

11 one proband was found to carry the D658G mutation reported, as the more recurrent disease-

12 causing allele.

Conclusions: Our findings suggest that WDR36 sequence variance are only rare causes of glaucoma in Italian families with glaucoma. Clearly, investigation of additional families with extensive studies are request to clarify the role of WDR 36 in the pathophysiology of glaucoma. 
1

2

\section{Introduction}

The term primary open-angle glaucoma (POAG) describes a heterogeneous group of optic neuropathies that lead to optic nerve atrophy and permanent loss of vision. ${ }^{1}$ It is the second most prevalent cause of bilateral blindness in the Western world and affected about 67 million subjects in the year 2000. ${ }^{2,3}$ POAG includes various clinical entities, such as ocular hypertension $(\mathrm{OH})$, glaucoma with elevated intraocular pressure (high tension glaucoma HTG-POAG) and normal tension glaucoma (NTG), juvenile open angle glaucoma (JOAG). ${ }^{1}$ Genetic factors play a major role in the aetiology of HTG-POAG. Up to now 14 loci (GLC1A > GLC1N) have been associated with POAG using linkage analysis. ${ }^{4}$ Some HTG-POAG families have mutations in the genes associated to GLC1A, GLC1E and GLC1G loci. Mutations in the myocilin gene (MYOC) at locus GLC1A, have been reported in $2-4 \%$ of HTG-POAG patients and in up to $33 \%$ of JOAG patients. ${ }^{5,6}$ In 2002, the Optineurin gene (OPTN), associated to GLC1E locus was identified. ${ }^{7}$ In the 54 families analysed with adult-onset HTG-POAG and in at least one member with NTG, OPTN mutations have been found in $16.7 \%$ of cases. ${ }^{8}$ In these families individuals with autosomal dominant NTG were present. In 2005 a new locus on chromosome 5q22 related to HTG-POAG and NTG was identified. $^{2}$ The associated gene, WDR36, was also identified. Sequence variations in the WDR36 gene were identified in approximately $5 \%$ of POAG cases. ${ }^{2}$ WDR36 is a member of the WD40 repeat protein family. WDR36 sequence variants can lead to an altered cellular phenotype supporting the theory that WDR36 partecipate in polygenic form of glaucoma. ${ }^{9}$ Interestingly, the T-cell mediated response has been in turn hypothesized to partecipate in optic nerve degeneration. ${ }^{10}$ The aim of this study was to define the frequency of WDR36 sequence variance in glaucoma Italian families. 
1 Methods and Patients

2

The study was performed in accordance with the tenets of the Declaration of Helsinki. The local ethics committee approved the study. To record the clinical characteristics of the patient, a standard form was provided and written informed consent was obtained from each participant. The project structure provides that a continuous enrolment of glaucoma patients was made for two years in 6 different Italian eye clinics (Siena, Torino, Milano, Cagliari, Roma, and Verona) in order to obtain a consistent population. DNA samples of 34 patients (index cases or probands) and 107 relatives were collected from the 6 centers located throughout Italy. Patients included in the study belonged to families in which at least two members were affected by POAG. The patients were questioned and records kept to determine family and personal history, age, sex, race, age at diagnosis, pedigree, medications used, prior laser and surgical procedures, co-existing systemic diseases.

Each patient underwent a complete ophthalmic evaluation: anterior segment examination, uncorrected and best-corrected visual acuity, gonioscopy with grading according to Van HerickShaffers-Schwartz grading system, ${ }^{11}$ fundus examination with indirect ophthalmoscopy, biomicroscopic analysis of the optic nerve head $(\mathrm{ONH})$ with a $78 \mathrm{D}$ lens and evaluation of the cup/disk ratio, intraocular pressure (IOP) measurement with Goldmann tonometer and visual field examination.

They were defined as "affected by glaucoma" if they fulfilled the following criteria: typical glaucomatous visual field (VF) loss on either Octopus or Humphrey perimetry and glaucomatous alterations of the $\mathrm{ONH}^{12}$

A visual field was classified as glaucomatous when: 1) three adjacent points depressed by 5 $\mathrm{dB}$, with one of the points depressed by at least $10 \mathrm{~dB}$; 2) two adjacent points depressed by $10 \mathrm{~dB}$; or 3) a $10 \mathrm{~dB}$ difference across the nasal horizontal meridian in two adjacent points. None of the points could be edge points unless immediately above or below the nasal horizontal meridian. ${ }^{12}$ In 
1 addition, visual field testing was considered reliable only when false-negative responses were less

2 than $30 \%$ and fixation losses were less than $20 \%{ }^{12}$ The perimetric defect type and stage evaluation

3 were performed using the Brusini's glaucoma staging system. ${ }^{13}$

$4 \quad$ POAG is characterized by progressive narrowing of the neuroretinal rim. An optic nerve head was

5 classified abnormal when it was present a $\mathrm{ONH}$ notch, or a concentric thinning of the neuroretinal

6 rim, or both in combination. ${ }^{14,15}$

7 At the end of the examination, glaucomatous patients were catalogued into three groups.

8 Patients were classified as POAG when they were 35 years and older and either typical

9 glaucomatous VF loss or glaucomatous alterations of the ONH. Based on the IOP values the POAG group was divided into two groups: HTG-POAG if an IOP $\geq 21 \mathrm{mmHg}$ and NTG-POAG if IOP <

$21 \mathrm{mmHg}$. If the patients were younger than 35 years and also an IOP $>21 \mathrm{mmHg}$ and either typical glaucomatous VF loss or glaucomatous alterations of the $\mathrm{ONH}$, they were classified as JOAG. ${ }^{1}$

Molecular analysis

Blood samples were collected from affected and healthy family members (total number of collected samples was 141). Genomic DNA was isolated from the peripheral blood leukocytes by using the QIAamp DNA Blood Kit according to the manufacturer protocol (Qiagen, www.qiagen.com). We used the OD260/280 method on a photometer to determine the appropriate DNA concentration. ${ }^{16}$ All 23 coding exons and flanking introns of the WDR36 gene were amplified using primers designed on intronic sequences (Table 1). Mutation analysis was performed by Denaturing High Performance Liquid Chromatography (DHPLC) using the Transgenomic WAVE $^{\mathrm{TM}} 3500$ HT (Transgenomic, San Jose, CA, USA;http://www.transgenomic.com) (Underhill PA et al Genome Res 7:996-1005, 1997). PCR product were denatured at $95^{\circ} \mathrm{C}$, reannealed at $65^{\circ} \mathrm{C}$ for 10 minutes, and cooled to $4^{\circ} \mathrm{C}$ to generate heteroduplexes. The optimal column temperature for fragments analysis was calculated using the WaveMaker Software (Transgenomic, San Jose, CA, 
1 USA). PCR and DHPLC analysis conditions are reported in Table 1. Direct sequencing of the

2 purified PCR products was performed in both directions (PE Big dye terminator cycle sequencing kit) on an ABI310 Automated Sequencer and analysed with the Sequencher software .

\section{Results}

Thirty-four familial cases were enrolled in the study from the 6 eye centers involved in the project. Number of affected members per family varied from 2 to 6 individuals. Analysis of the pedigrees suggested an autosomal dominant inheritance in all families. A total number of 141 subjects underwent to accurate clinical examination. The clinical examination allowed us to define 69 affected individuals ( 37 females and 32 males). Among the 34 enrolled families, 25 were affected by HTG-POAG, 4 by JOAG and 1 by NTG-POAG. In addition, 4 families presented both JOAG patients and HTG-POAG patients within the same pedigree.

DHPLC mutation analysis of WDR36 gene was performed in the 34 probands of above reported families. In all families mutation in MYOC gene and in OPTN gene were previously excluded $^{6}$ (and personal data). The following intronic variants have been identified: IVS12+190 G>T; IVS13+89G>A; IVS16-30A>G. None of these variants segregate with the disease in the families. The following four already known intronic polymorphisms were found: IVS5+30C $>$ T; IVS12+90 G>T; IVS13+89G>A; IVS16-30A>G. ${ }^{2}$ In addition, a novel polymorphism was found: IVS21-75G $>$ A. This change was present in our population in $13 \%$ of patients and $14 \%$ of controls.

One proband was found to carry the D658G mutation reported as the more recurrent diseasecausing allele. ${ }^{2}$ The proband, aged 58 years, was affected by HTG-POAG, with an age at diagnosis of 45 years (Fig. 1). He had three sons, one female and two males, aged, 35, 32 and 28 years, respectively. In the sons, ocular hypertension started at 20, at 19 and 27 years, respectively and it was controlled by antihypertensive treatment. Segregation analysis showed that the mutation was inherited only by the youngest son (Fig. 1). 


\section{$1 \quad$ Discussion}

2 The aim of this study was to define the involvement of WDR36 sequence variance in glaucoma

3 Italian families. We previously demonstrated that in the Italian population, about $6 \%$ of the familial cases with primary open angle glaucoma has a mutation in MYOC gene. ${ }^{7}$ On the contrary, no mutations were found in OPTN gene. ${ }^{17}$ Since the WDR36 gene has been recently reported as the third glaucoma-causing gene, we decided to evaluate which fraction of Italian cases is due to this new gene. We did not find any pathogenic mutation in our cohort of patients. We identified only intronic polymorphisms. In one family we identified the D658G mutation, previously reported as the more recurrent disease-causing allele. ${ }^{17}$ Furthemore, in the four families in which we found JOAG and POAG, we can supposed that glaucoma onset was different among the family members, but the disease was likely the same. The different classification was due to the classification methods, that we use in clinical practice, indeed the main different between POAG and JOAG is the glaucoma onset. ${ }^{1}$

Hauser et al analyzed a large cohort of patients with glaucoma for mutations in WDR36 gene. They found several nonsynonymous single-nucleotide polymorphisms, including those previously described as "disease-causing" and "disease susceptibility," in both patient and control subjects. ${ }^{10}$ They concluded that abnormalities in WDR36 were not sufficient alone to cause HTGPOAG.

In 2006, Pang et al mapped a new locus for juvenile open angle glaucoma in 5q22.1-q32. ${ }^{18}$ They described a region of maximum lod score located telomerically with respect to WDR36, by studying a family with 27 members, in which 9 were confirmed JOAG patients. The analysis of the WDR36 coding sequence did not reveal any pathogenic mutation and it definitively excluded the involvement of this gene in generating the phenotype.

In 2008, Pasutto et al recruited 399 patients with glaucoma and 376 healty subjects and investigated the prevalence of WDR36 variants in German populations. ${ }^{19}$ A total of 44 WDR36 allelic variants were detected but the occurrence of several rare putative disease causing variants in 
1 patients with glaucoma suggested to the authors that WDR36 may be a minor disease causing gene in glaucoma at least in the German population.

In Hauser et al. HTG-POAG patients WDR36 sequence variations were associated with a more severe disease phenotype than those without, suggesting that the sequence variants in WDR36 may play a role in disease susceptibility rather than causation. ${ }^{10}$

POAG is a disease with a complex inheritance that is likely to result from contributions of multiple genes and possibly environmental conditions. Mendelian autosomal dominant and recessive forms of glaucoma are caused by single gene defects but the genetic etiologies results from contributions of multiple genetic factors that independently are able to cause the disease. Genes that contribute to POAG may not cause clinical evidence of the disease unless they are coupled with other genes or environmental factors. For this reason the identification of any one disease-predisposing factor can be difficult when using traditional linkage approaches. Our findings suggested that WDR36 sequence variance were only rare causes of glaucoma in Italian families with glaucoma. Clearly, investigation of additional families with extensive studies are request to clarify the role of WDR 36 in the pathophysiology of glaucoma. It is very important the identification of susceptibility and glaucoma modifying genes for the complete genetic and molecular understanding of POAG, for this reason the European Glaucoma Society has a project to create an European genetic database to better study the glaucoma phenotypes. ${ }^{20}$ 


\section{References and acknowledgements}

1. European Glaucoma Society. Terminology and guidelines for glaucoma. 3rd ed. Savona: editrice Dogma 2008, Chapter 2:95-97.

2. Quigley HA. Number of people with glaucoma worldwide. Br J Ophthalmol. 1996;80:389393.

3. Klaver CC, Wolfs RC, Vingerling JR, Hofman A, de Jong PT. Age specific prevalence and causes of blindness and visual impairment in an older population: The Rotterdam Study. Arch Ophthalmol. 1998;116:653-658.

4. Allingham RR, Liu Y, Rhee DJ, The genetics of primay open-angle glaucoma: A review, Exp Eye Res. 2009;88;837-844:1-8.

5. Libby RT, Gould DB, Anderson MG, et al. Complex genetics of glaucoma susceptibility. Annu Rev Genomics Hum Genet. 2005;6:15-44.

6. Fingert JH, Heon E, Liebmann JM, et al. Analysis of myocilin mutations in 1703 glaucoma patients from five different populations. Hum Mol Genet. 1999;8:899-905.

7. Bruttini M, Longo I, Frezzotti P, et al. Mutations in the myocilin gene in families with primary open-angle glaucoma and juvenile open-angle glaucoma. Arch Ophthalmol. $2003 ; 121: 1034-8$.

8. Rezaie T, Child A, Hitchings et al. Adult-Onset Primary Open-Angle Glaucoma Caused by Mutations in Optineurin. Science 2002; 295:1077-9.

9. Footz TK, Johnson JL, Dubois S et al. Glaucoma associated WDR36 variants encode functional defects in a yeast model system. Hum Mol Genet. 2009;18:1276-87.

10. Hauser MA, Allingham RR, Linkroum K, et al. Distribution of WDR36 DNA sequence variants in patients with primary open-angle glaucoma. Invest Ophthalmol Vis Sci. 2006;47:2542-6.

11. Van Herick W, Shaffer RN, Schwartz A. Estimation of width of angle of anterior chamber. Incidence and significance of the narrow angle. Am J Ophthalmol. 1969;68:626-9. 
12. Iester M, Swindale NV, Mikelberg FS. Sector-based analysis of optic nerve head shape parameters and visual field indices in healthy and glaucomatous eyes. J Glaucoma 1997;6:371-376.

13. Brusini P. Clinical use of a new method for visual field damage classification in glaucoma. Eur J Ophthalmol. 1996;6:402-7.

14. European Glaucoma Society. Terminology and guidelines for glaucoma. 3rd ed. Savona: editrice Dogma,2008, Chapter 1:75-76.

15. Tuulonen A., Airaksinen PJ. Initial glaucomatous optic disk and retinal nerve fiber layer abnormalities and their progression. Am J Ophthalmol. 1991;111:485-90.

16. Monemi S, Spaeth G, DaSilva A, et al. Identification of a novel adult-onset primary openangle glaucoma (POAG) gene on 5q22.1. Hum Mol Genet. 2005;14:725-33.

17. Ariani F, Longo I, Frezzotti P, et al. Optineurin gene is not involved in the common hightension form of primary open-angle glaucoma. Graefes Arch Clin Exp Ophthalmol. 2006;244:1077-82

18. Pang CP, Fan BJ, Canlas O, et al. A genome-wide scan maps a novel juvenile-onset primary open angle glaucoma locus to chromosome 5q. Mol Vis. 2006;12:85-92.

19. Pasutto F, Mardin CY, Michels-Rautenstrauss K et al. Profiling of WDR 36 Missense Variants in German Patients with Glaucoma. Invest Ophthalmol Vis Sci 2008;49:270-274.

20. Founti P, Topouzis F, van Koolwijk L, et al. Biobanks and the importance of detailed phenotyping: a case study--the European Glaucoma Society GlaucoGENE project. $\mathrm{Br} J$ Ophthalmol. 2009;93:577-81. 
$1 \quad$ Figure legends

2 Figure1: Segregation analysis of D658G change.

3 The proband and the youngest son have the same mutation. On the contrary the other two sons do

4 not bear mutation. Symbols, white $=$ unaffected subjects, black = glaucoma, grey $=$ ocular

5 hypertension. 
1 Tables

2 Table 1. Oligonucleotides primers and PCR/DHPLC conditions for WDR36 analysis.

\begin{tabular}{|c|c|c|c|c|}
\hline Exon & $\begin{array}{l}\text { Forward primer sequence } \\
\text { Reverse primer sequence }\end{array}$ & $\begin{array}{c}\mathrm{PCR} \\
\mathrm{T}_{\mathrm{m}}\end{array}$ & $\begin{array}{c}\text { DHPLC } \\
\mathrm{T}_{\mathrm{m}}\end{array}$ & $\begin{array}{c}\text { DHPLC } \\
\% \mathrm{~B}\end{array}$ \\
\hline 1 & 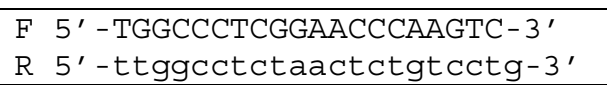 & $65^{\circ}$ & $\begin{array}{l}61.4^{\circ} \\
63.4^{\circ}\end{array}$ & $59.8^{4}$ \\
\hline 2 & $\begin{array}{l}\mathrm{F} 5^{\prime} \text {-ttcttatgaaggacagcatagc-3' } \\
\mathrm{R} 5^{\prime} \text {-agggtgccaggataaatcatg-3' }\end{array}$ & $62^{\circ}$ & $54^{\circ}$ & 56.95 \\
\hline 3 & $\begin{array}{l}F \quad 5^{\prime} \text {-aatgttatatgtatacttgagg-3' } \\
R \text { 5'-tagtggagggaactttaatt-3' }\end{array}$ & $56^{\circ}$ & $\begin{array}{l}55.4^{\circ} \\
57.4^{\circ}\end{array}$ & 55 \\
\hline 4 & $\begin{array}{l}\mathrm{F} 5^{\prime} \text {-agaagcatctcaggattagc }-3^{\prime} \\
\mathrm{R} \text { 5'-aaacatctatgccagagattt }-3^{\prime}\end{array}$ & $52^{\circ}$ & $54.6^{\circ}$ & 57 \\
\hline 5 & $\begin{array}{l}\text { F 5'-catttacaagttgcctctca-3' } \\
\text { R } 5^{\prime} \text {-cttaagtctcatttctccct-3' }\end{array}$ & $56^{\circ}$ & $53^{\circ}$ & 59.2 \\
\hline 6 & $\begin{array}{l}\mathrm{F} 5^{\prime} \text {-atacagctttcaactatttttc-3' } \\
\mathrm{R} \text { 5'-ctgaggaaatagtgttttgga-3' }\end{array}$ & $52^{\circ}$ & $55^{\circ}$ & 54.5 \\
\hline $7{ }^{8}$ & $\begin{array}{l}\text { F 5'-gcgtatcatcaggattatta-3' } \\
\text { R 5'-tcttcctggctcatctaact-3' }\end{array}$ & $56^{\circ}$ & $\begin{array}{l}53.2^{\circ} \\
54.2^{\circ}\end{array}$ & 62.3 \\
\hline 9 & $\begin{array}{l}\mathrm{F} \text { 5'-cttgcagatcagatggaaca-3' } \\
\mathrm{R} \text { 5'-cagcaagtattgagatgtgg-3' }\end{array}$ & $58^{\circ}$ & $56.7^{\circ}$ & 54.1 \\
\hline 10 & $\begin{array}{l}F \quad 5^{\prime} \text {-aatttgtgattcacatagtc-3' } \\
R \quad 5^{\prime} \text {-gctggtcacgaaagaaac-3' }\end{array}$ & $56^{\circ}$ & $55^{\circ}$ & 51.4 \\
\hline 11 & $\begin{array}{l}\text { F 5'-aggattcatagctatgtatg-3' } \\
\text { R 5'-taagcattcagaaggtaacc-3' }\end{array}$ & $52^{\circ}$ & $\begin{array}{l}55.1^{\circ} \\
56.1^{\circ}\end{array}$ & 55.1 \\
\hline 12 & $\begin{array}{l}F \quad 5^{\prime} \text {-cattgtatccctagtgtctga-3' } \\
R \text { 5'-gctcctgtgacttctaagag-3' }\end{array}$ & $60^{\circ}$ & $\begin{array}{l}54.1^{\circ} \\
56.5^{\circ}\end{array}$ & 59.3 \\
\hline 13 & $\begin{array}{l}\text { F 5'-tgctttggaaagcataaagt-3' } \\
\text { R 5'-gatgggttataatcaaccct-3' }\end{array}$ & $52^{\circ}$ & $54.8^{\circ}$ & 57.1 \\
\hline $14 \_15$ & $\begin{array}{l}\mathrm{F} \text { 5'-ctgtgtgtattgttcagag-3' } \\
\mathrm{R} \text { 5'-acttgactcatttctacttt-3' }\end{array}$ & $53^{\circ}$ & $55.5^{\circ}$ & 61.7 \\
\hline 16 & $\begin{array}{l}\text { F 5'-aggcagcctgaatgttag-3' } \\
\text { R 5'-cgatagttaatgggttatatg-3' }\end{array}$ & $55^{\circ}$ & $50.5^{\circ}$ & 58 \\
\hline 17 & $\begin{array}{l}\text { F 5'-ctgcatctcttatcccttat-3' } \\
\text { R 5'-cttaattcactgtaagtctg-3' }\end{array}$ & $55^{\circ}$ & $\begin{array}{l}53.9^{\circ} \\
55.9^{\circ}\end{array}$ & 58.2 \\
\hline 18 & $\begin{array}{l}\mathrm{F} 5^{\prime} \text {-caatctatctttgaggtatt-3' } \\
\mathrm{R} 5^{\prime} \text {-tgtaggagatattgctacca-3' }\end{array}$ & $54^{\circ}$ & $53.2^{\circ}$ & 56.5 \\
\hline 19 & $\begin{array}{l}\text { F 5'-ttgatgtggtattgataagc-3' } \\
\text { R 5'-gcattagaagagcaattaa-3' }\end{array}$ & $52^{\circ}$ & $53.8^{\circ}$ & 60.5 \\
\hline $20 \_21$ & $\begin{array}{l}\mathrm{F} \text { 5'-ggtattggtcagaagagatca-3' } \\
\mathrm{R} \text { 5'-ggaaatatcagcgttctcagt-3' }\end{array}$ & $60^{\circ}$ & $53.5^{\circ}$ & 61.9 \\
\hline 22 & $\begin{array}{l}\text { F 5'-cacaggaagaatttcctgta-3' } \\
\text { R 5'-ccagcttgtcttcttctgg-3' }\end{array}$ & $57^{\circ}$ & $53.1^{\circ}$ & 58.1 \\
\hline 23 & $\begin{array}{ll}\mathrm{F} & 5^{\prime} \text {-tcacctagtgtcttttgtg-3' } \\
\mathrm{R} & 5^{\prime} \text {-CCAAGTGTCAATGTGAAAAG-3' }\end{array}$ & $55^{\circ}$ & $\begin{array}{l}53.8^{\circ} \\
55.8^{\circ}\end{array}$ & 57.7 \\
\hline
\end{tabular}




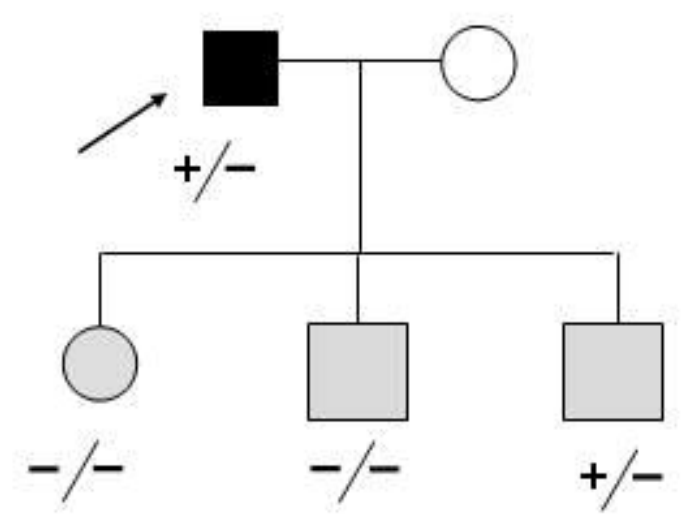

Fig.1 